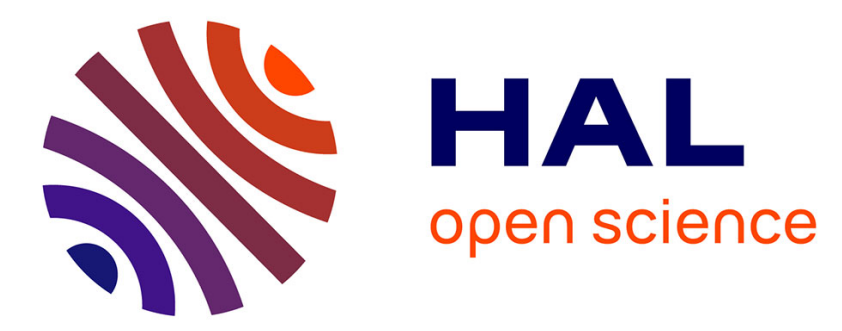

\title{
Tailoring Strain and Morphology of Core-Shell SiGe Nanowires by Low-Temperature Ge Condensation
}

Thomas David, Kailang Liu, Antoine Ronda, Luc Favre, Marco Abbarchi, Marc Gailhanou, Pascal Gentile, Denis Buttard, Vincent Calvo, Michele Amato, et al.

\section{To cite this version:}

Thomas David, Kailang Liu, Antoine Ronda, Luc Favre, Marco Abbarchi, et al.. Tailoring Strain and Morphology of Core-Shell SiGe Nanowires by Low-Temperature Ge Condensation. Nano Letters, 2017, 17 (12), pp.7299 - 7305. 10.1021/acs.nanolett.7b02832 . hal-01788664

\section{HAL Id: hal-01788664 https://hal.science/hal-01788664}

Submitted on 22 May 2018

HAL is a multi-disciplinary open access archive for the deposit and dissemination of scientific research documents, whether they are published or not. The documents may come from teaching and research institutions in France or abroad, or from public or private research centers.
L'archive ouverte pluridisciplinaire HAL, est destinée au dépôt et à la diffusion de documents scientifiques de niveau recherche, publiés ou non, émanant des établissements d'enseignement et de recherche français ou étrangers, des laboratoires publics ou privés. 


\title{
Tailoring strain and morphology of core-shell SiGe nanowires by low temperature Ge condensation
}

\author{
Thomas David, ${ }^{* \dagger}$ Kailang Liu, ${ }^{\dagger}$ Antoine Ronda, ${ }^{\dagger}$ Luc Favre, $^{\dagger}$ Marco Abbarchi, ${ }^{\dagger}$ \\ Marc Gailhanou, ${ }^{\dagger}$ Pascal Gentile, ${ }^{\ddagger}$ Denis Buttard, ${ }^{\ddagger}$ Vincent Calvo, ${ }^{\ddagger}$ Michele \\ Amato, "Jean-Noël Aqua, ${ }^{\S}$ and Isabelle Berbezier ${ }^{\dagger}$ \\ $\dagger$ †Aix-Marseille Univ. - CNRS, IM2NP, Faculté des Sciences de Jérôme, F-13397 Marseille \\ France \\ $\ddagger$ Univ. Grenoble Alpes, CEA INAC-Pheliqs-SiNaPS, F-38000 Grenoble, France \\ ฯLaboratoire de Physique des Solides and Centre de Nanosciences et de Nanotechnologies, \\ CNRS, Univ. Paris-Sud, Université Paris-Saclay, 91405 Orsay, France \\ $\S I N S P$; Boite 840; 4 pl. Jussieu; 75005 Paris \\ E-mail: thomas.david@im2np.fr \\ Phone: + 33 (0) 491289163
}

\section{Abstract}

Selective oxidation of the silicon element of silicon germanium ( $\mathrm{SiGe}$ ) alloys during thermal oxidation is a very important and technologically relevant mechanism used to fabricate a variety of microelectronic devices. We develop here a simple integrative approach involving vapor-liquid-solid (VLS) growth followed by selective oxidation steps to the construction of core-shell nanowires and higher-level ordered systems with scalable configurations. We examine the selective oxidation/condensation process under non-equilibrium conditions that gives rise to spontaneous formation of coreshell structures by germanium condensation. We contrast this strategy that uses reactiondiffusion-segregation mechanisms to produce coherently strained structures with highly configurable geometry and abrupt interfaces with growth-based processes which lead to low strained systems with non-uniform composition, 3D morphology and broad core-shell interface. We specially focus on SiGe core-shell nanowires and demonstrate that they can have up to $70 \%$ Ge- rich shell and $2 \%$ homogeneous strain, with core diameter as small as $14 \mathrm{~nm}$. Key elements of the building process associated with this approach are identified with regard to existing theoretical models. Moreover, starting from results of ab initio calculations, we discuss the electronic structure of these novel nanostructures as well as their wide potential for advanced device applications.

\section{Introduction}

SiGe core-shell nanowires (NWs) open tantalizing routes for hybrid, high-performance circuits where NW devices with different functionality could be easily integrated with the current Si-based technology. ${ }^{1}$ In this context, most of the attention has been dedicated to the development of field effect transistors. ${ }^{2-5}$ In the last decade, SiGe core-shell NWs have attracted a great interest from basic science studies to fascinating applications. ${ }^{1,6-11}$ The remarkable sustained advancement in the understanding of their superior performances over the 
homogeneous Si counterpart has been used to guide the fabrication processes. ${ }^{8,12-14}$ However, despite the large number of studies dedicated to top-down, bottom-up fabrications or a combination of both processes, the experimental realization of direct band-gap systems using rational engineering processes is still far to be achieved. Specific NW geometries that could tailor the electronic properties have been identified. ${ }^{2,15}$ They can be custom-designed at the nanoscale by strain engineering using specific growth mechanisms. ${ }^{16}$ However, when NW diameters reach nanoscale dimensions, detrimental behaviors such as axial and tangential strain relaxation, quantum dots formation, interdiffusion and surface roughening are observed. ${ }^{17-20}$ A particular focus has been put on the coreshell interface broadening and the strain relaxation/strain sharing between core and shell. ${ }^{21-23}$ Moreover, 2D quantum confinement effects and strain band-gap engineering are exploited in order to achieve improved opto-electronic performances ${ }^{24-28}$ and thermoelectric efficiency. ${ }^{29-37}$

Band-gap strain engineering of planar systems structures is efficiently used for ultra-thin Silicon On Insulator (SOI) based devices to provide compressive tensile strain. The use of new materials including germanium, III-Vs or new dielectrics is also under investigation. ${ }^{38-42}$ Next-generation transistors are expected to employ strained SiGe ultra-short channels made on $\mathrm{SOI}^{43,44}$ while longer-term strategies involve a change in geometry with multi-gates and surrounding gates. ${ }^{7,45}$ In this context, core-shell NWs are an exceptional playground to test and understand the physical properties of nanostructures with a cylindrical geometry.

Fabrication of core-shell NWs is mostly done by a two-step process. First, a bottom-up growth method ${ }^{46}$ or top-down nanofabrication such as ultimate resolution etching techniques. ${ }^{47}$ Second, the deposition of a the shell material all around the core. Concerning SiGe NWs, they can be grown by VLS chemical vapor deposition (CVD) using gold catalysts, followed by non-catalyzed CVD deposition. ${ }^{6,48}$ A big challenge in this approach is the conformal epitaxial deposition of a surrounding material (the shell) around a cylindrical ob- ject (the core). Heteroepitaxy is very challenging in the case of flat layers, but with cylindrical geometry, the mechanism involved can be strongly modified by the very small curvature radius of the surface, especially considering strain-related and diffusion-based mechanisms. In a previous study, we demonstrated that the germanium condensation occurring during oxidation of SiGe at relatively low temperatures (around $750{ }^{\circ} \mathrm{C}$ ) can be used on thin layers to create sharp heterointerfaces with perfect crystalline quality without plastic or elastic strain relaxation. ${ }^{49,50}$

In this work, we use the same condensation process to form a germanium rich shell (GRS) around CVD-grown SiGe NWs. The main advantages of this process are: (i) a reduction of the diameter of the initial NW, (ii) a perfectly conformal geometry with a flat surface, an abrupt interface and a Ge rich shell (70-80\% Ge concentration never previously experienced) without formation of quantum dots nor extended defects. This process gets rid of defects at the interface between the core and the shell of the final NWs which is located in the body of the initial monocrystalline SiGe nanowire. The silicon oxide thermally grown around the GRS guarantees a perfect surface passivation which could be crucial for sensing and biological applications. ${ }^{51}$ Furthermore, through atomistic first principles simulations, we demonstrate that these novel nanostructures have interesting electronic properties that may improve performances of NWs-based opto-electronic devices.

\section{Experimental details}

The core of the nanowire is produced by VLS growth using CVD, while the shell is subsequently formed by thermal oxidation of the SiGe NWs.

SiGe NWs cores with less than $30 \%$ germanium are grown in a low pressure reactor (EasyTube3000 First Nano, a Division of CVD Equipment Corporation) via gold catalyst on $\mathrm{Si}$ (111) and Ge (111) substrates. $\mathrm{H}_{2}$ is used as carrier gas, silane $\left(\mathrm{SiH}_{4}\right)$ and germane $\left(\mathrm{GeH}_{4} 10 \%\right.$ in $\left.\mathrm{H}_{2}\right)$ as silicon and ger- 
manium precursors and $\mathrm{HCl}$ as additive gas to reduce the gold surface migration and improve the NWs morphology. ${ }^{52-54}$ Gold colloids were used to calibrate the NWs diameters typically here $100 \mathrm{~nm}$. The growth conditions are: total pressure 6 Torr, temperature $450{ }^{\circ} \mathrm{C}, \mathrm{H}_{2}$ flux $0.7 \mathrm{l} / \mathrm{mn}$, silane flux $90 \mathrm{sccm}$, germane flux $15 \mathrm{sccm}, \mathrm{HCl}$ flux $100 \mathrm{sccm}$ and duration $40 \mathrm{mn}$ for $7 \mu \mathrm{m}$ NW length.

The oxidations to form the shell are performed in a rapid thermal oxidation (RTO) furnace JIPELEC at $750{ }^{\circ} \mathrm{C}$; the duration was varied between $0.5 \mathrm{~h}$ and $1.5 \mathrm{~h}$ by steps of $30 \mathrm{~min}$ in accordance with the RTO technical specifications. During this oxidation, a GRS is formed together with an outer shell of silicon oxide. As a result, we obtain perfectly crystalline coreshell SiGe nanowires embedded in silicon oxide with a strain induced by the difference of germanium concentration (and thus of lattice parameter) between the core and the shell. The core of the NW keeps the initial low Ge concentration, while the shell has a very high Ge content (more than 70\%).

Starting from NWs of a diameter of $100 \mathrm{~nm}$, we can obtain various thicknesses of shell with respect to the diameter of the final core by adjusting the temperature and duration of the oxidation. Core-shell NWs with a total diameter smaller than $30 \mathrm{~nm}$ were thus fabricated.

Transmission Electron Microscopy (TEM) is done using a FEI Tecnai G2, and a FEI Titan 80-300 with Cs corrector in TEM and Scanning Transmission Electron Microscopy (STEM) modes. In STEM mode, we can use a High Angular Annular Dark-Field (HAADF) detector in order to have a purely chemical contrast with the light elements being dark on the image. Energy Dispersive Spectroscopy X-ray (EDX) analysis are performed with the FEI Titan 80-300 with Cs corrector using a probe size of approximately $1 \mathrm{~nm}$ or the FEI Tecnai G2 using a probe size of approximately 2-3 $\mathrm{nm}$. The $\mathrm{k}$ factors of $\mathrm{Si}, \mathrm{Ge}$ and $\mathrm{O}$ are measured on reference samples and allow the determination of absolute concentrations. Transmission electron samples are prepared using a dualbeam FIB FEI HELIOS 600 nanolab. For the TEM observations of slices, the NWs are dry- transferred on a silicon substrate where a standard TEM lamela is prepared by FIB perpendicularly to the axis of the nanowire.

\section{Results and Discussion}

Fig. 1a gives a schematic representation of the core-shell formation by Ge condensation mechanism. ${ }^{49,50}$ Compared to a traditional two step growth process, the main advantage of this method is the perfect abruptness of the core-shell interface. At the end of the process, this interface is located in the body of the initial SiGe nanowire which rules out the presence of impurities or defects. Furthermore, the surface of the GRS is fully covered by the embedding silicon oxide which provides a well-passivated structure.

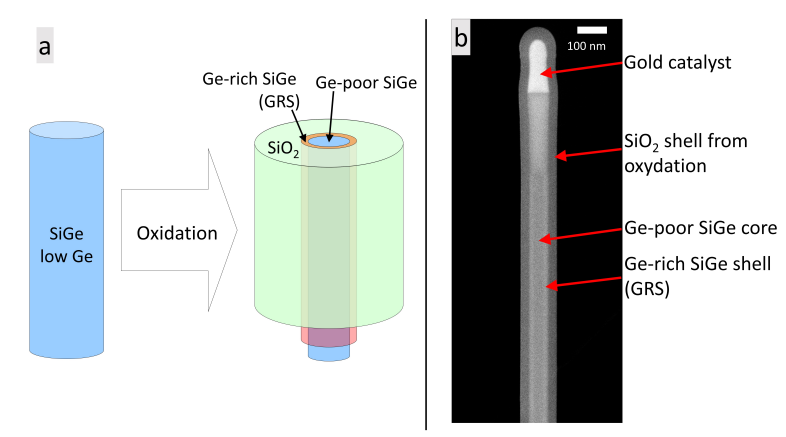

Figure 1: (a) Schematic of the the core-shell formation by oxidation of a SiGe nanowire with a low initial concentration of Ge. (b) SEM image of a nanowire after oxidation. A contrast is visible between the core, the catalyst, the shell and the $\mathrm{SiO}_{2}$ all-around. Partial transparency through the nanowire results from the high acceleration voltage used for the SEM image $(20 \mathrm{kV})$.

A typical example of a NW after oxidation is given in Fig. 1b, which shows a SEM image at $20 \mathrm{kV}$ of a nanowire after the fabrication of the shell. Various contrasts inside the nanowire highlight the different layers: the Si-rich core, the Ge-rich shell and the surrounding oxide. This final geometry corresponds the schematic representation of Fig. 1a. Surprisingly, at the top of the nanowire the gold catalyst is also completely embedded inside the $\mathrm{SiO}_{2}$. This 
layer is ascribed to the oxidation of the $\mathrm{Si}$ rejected by the liquid droplet during cool-down after the growth. ${ }^{55}$
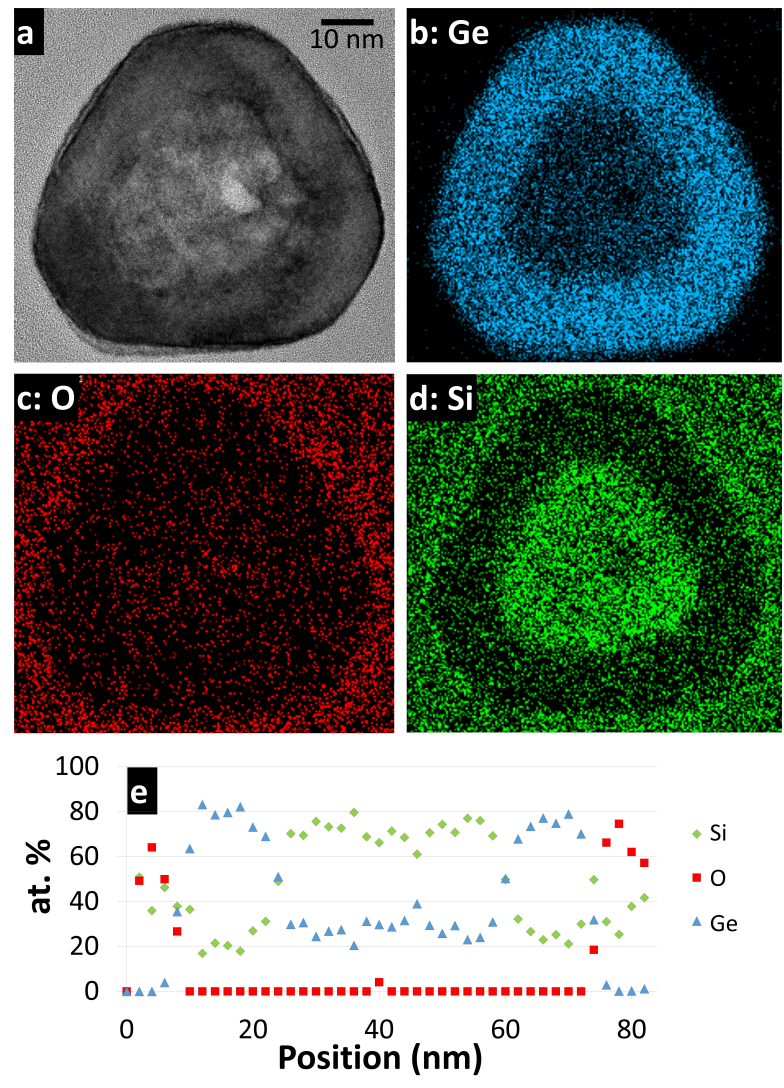

Figure 2: (a) TEM image of a slice of nanowire. (b),(c) and (d) EDX maps of germanium (blue), oxygen (red) and silicon (green) respectively. (e) Vertical Line profile in the middle of the image showing $\mathrm{Si}, \mathrm{O}$ and $\mathrm{Ge}$ concentrations. The average germanium concentration in the core is $30 \%$ and $70 \%$ in the shell. The presence of oxygen all over the cross-section image is ascribed to the native oxide on the TEM lamella.

Fig. 2 shows a cross-section of a core-shell nanowire with a quite large diameter to facilitate the line profile analysis. The initial faceting of the as grown nanowire with (112) facets is still well visible even if the facets have been rounded by the oxidation step. EDX maps of Ge, O and Si (Fig. 2b, c and d respectively) emphasizes the $\mathrm{SiO}_{2}$ outer shell, the Ge-rich shell and the Si-rich core. Fig. 2e shows a vertical line profile in the middle of the nanowire and allows to determine that the average Ge concentration in the core is $30 \%$ (which corresponds exactly to the as-grown concentration), while in the shell it is around $70 \%$.

This GRS quasi-cylindrical layer corresponds to the germanium rich layer (GRL) obtained by selective oxidation/condensation of SiGe thin films. However, in the latter case, the Ge concentration of the pile-up layer stabilizes at $50 \%$ while here it reaches $70 \% .{ }^{49,50,56}$ This remarkable high Ge concentration could be ascribed to different parameters, two of which have a particular importance: the cylindrical geometry and the crystal orientation (SiGe NWs are grown on $\operatorname{Si}(111))$.

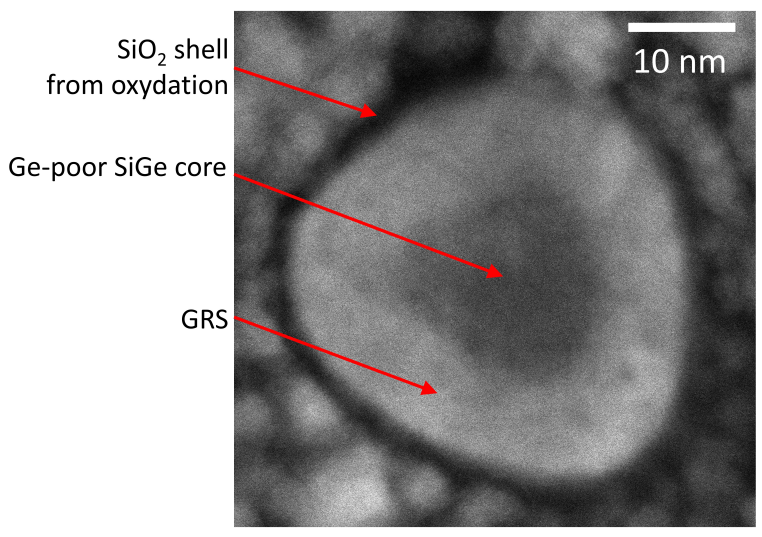

Figure 3: STEM-HAADF image of a small diameter core-shell nanowire. The diameter of the $\mathrm{Si}_{0.7} \mathrm{Ge}_{0.3}$ core is around $14 \mathrm{~nm}$ and the thickness of the $\mathrm{Si}_{0.3} \mathrm{Ge}_{0.7}$ shell is around 7$8 \mathrm{~nm}$.

Fig. 3 shows a STEM-HAADF image of a small diameter (around $21 \mathrm{~nm}$ ) NW. The HAADF contrast with darker core and lighter shell is representative of the different Ge concentration between the core and the shell. This is in good agreement with EDX measurement presented in Fig. 2. The initial nanowire faceting is less visible on this small size due to the reduced extension of the facets even if the overall shape resembles a rounded triangle. One can note here the small dimensions of the core and shell - $14 \mathrm{~nm}$ in diameter and $7 \mathrm{~nm}$ in thickness, respectively - which could be responsible for quantum confinement effects on electrons. ${ }^{10,57-59}$

Fig. 4a shows a HRTEM image of a larger nanowire after the same condensation process than the one performed above (Fig. 3). Looking 

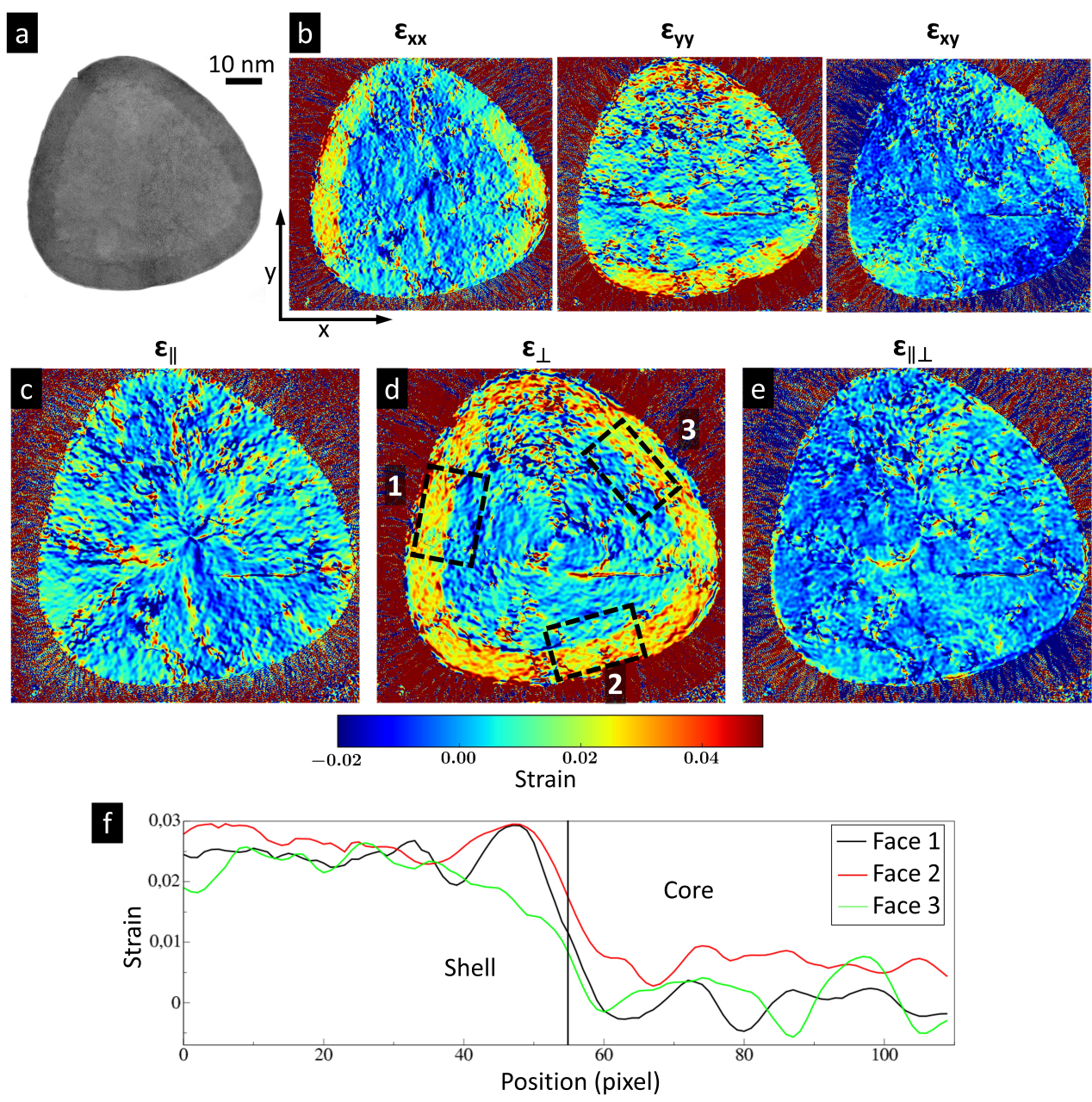

Figure 4: (a) High resolution TEM image of a slice of a nanowire. The oxide all-around was masked for clarity. (b) Components of the strain difference in the crystal calculated by GPA with a reference in the core of the nanowire. (c), (d) and (e) Local parallel, perpendicular and shear components of the strain respectively. (f) Plot of the perpendicular strain between the core and the shell integrated over three rectangular regions on the three faces of the nanowire (each face number is indicated on the image of panel $(\mathrm{d})$.

at the figure, it is clear that that the thickness of the shell is the same (around 7-8 nm) whatever the initial diameter is, and thence that the oxidation rate in these experimental conditions is not affected by the small diameter of NWs contrary to previous results. ${ }^{60}$ The $7-8$ nm-thick GRS appears darker, perfectly crystalline and in epitaxy on the $\mathrm{Si}_{0.7} \mathrm{Ge}_{0.3}$ core in the middle, also perfectly crystalline. The silicon oxide all around was masked out for clarity.

Geometric phase analysis (GPA) ${ }^{61}$ of this image was performed with a reference near the center of the core and allowed to extract strain maps. Fig. 4b shows the components of the GPA strain $\epsilon$ in Cartesian coordinates (see Sup- porting Information, paragraph 4, to see how the GPA strain is related to the real elastic strain). Due to the nearly cylindrical geometry of the NWs, such coordinates are not relevant and we choose another basis.

In fact, we can see the shell as a thin film which is rolled up around the core with an 'inplane' axis which is parallel to the interface and an 'out-of-plane' axis which is perpendicular, and thus define for every point a local reference frame. In our case, the shape of the section of the nanowire was modeled by an analytical curve and local parallel $\epsilon_{\|}$, perpendicular $\epsilon_{\perp}$ and shear $\epsilon_{\| \perp}$ components of the strain were obtained doing a change of basis (see Supporting In- 
formation for details) and are shown in Fig. 4c, $\mathrm{d}$ and e respectively. The $\epsilon_{\|}$component of the GPA strain tensor is close to 0 in the shell and in the core meaning that there is a lattice continuity at the interface between core and shell, i.e. the core-shell is pseudomorphic.

Considering the shell as a thin $\mathrm{Si}_{0.3} \mathrm{Ge}_{0.7}$ layer pseudomorphic on a (112) $\mathrm{Si}_{0.7} \mathrm{Ge}_{0.3}$ substrate, a perpendicular strain of $2.45 \%$ is obtained from elasticity theory assuming the linearity of elastic constants and lattice parameters in the SiGe alloys. In the case of the present core shell nanowire, we expect a decrease of this value first because the nanowire may relax along its axis: The core may take a larger lattice parameter in this direction to decrease the shell elastic energy. A rough estimation of this effect using elasticity theory leads to a new value of the perpendicular strain around $2.35 \%$. Second, the surface curvature may also decrease this value but only slightly as at the center of each of the 3 faces the surface is nearly flat. Surface stress may also modify the strain but considering the nanowire cross section dimension it was estimated that this effect would be small. Fig. 4f shows three profiles of the perpendicular strain $\epsilon_{\perp}$ for the three faces of the nanowire (the three rectangles of integration are drawn on Fig. 4d). The average value of the perpendicular strain is $2.2 \%$, close to the value estimated above using the composition obtained from EDX measurements and elasticity theory assuming a pseudomorphic state of the shell. The absence of visible defects confirms this pseudomorphic state and shows further the coherence of the present core-shell nanowire composition/strain state analysis.

As is known, the wide interest in the employment of SiGe NWs as building blocks for advanced technological devices relies on some specific electronic properties that they present and that differ from the ones of the corresponding pure Si NWs and bulk systems. To obtain accurate information about the electronic structure of the SiGe core-shell NWs produced in this work, we performed atomistic ab initio calculations in the framework of Density Functional Theory (DFT) whose computational details are presented in the Supporting Information. The aim of these simulations is to give a qualitative description of the electronic structure of a such graded composition core-shell material. Indeed, while a large number of theoretical and experimental studies have been devoted to the investigation of pure Si/pure Ge core-shell NWs and pure Ge/pure Si core-shell NWs ${ }^{10,62}$ less much is known about structures with non uniform Ge composition in both core and shell.

Due to the huge computational needs of DFT in studying nanostructures, we have not been able to simulate NWs having the same size of the structures described above. We focused our attention instead on small diameters NWs (less than $3 \mathrm{~nm}$ ). Though apparently far from the experimental systems, many theoretical works in the past (see, for example, Refs. ${ }^{63-66}$ ) have pointed out how, in SiGe NWs, such small diameter models can correctly reproduce qualitative features of the electronic structure of larger objects. In addition, the condensation process could produce much smaller core-shell NWs with similar structure, composition and morphology if the oxidation is performed for a longer time. Only the core-shell aspect ratio will be changed with a thicker shell and a thinner core and a reduced total diameter, in the range of the diameters considered theoretically.

We considered $<111>$ oriented structures with a diameter ranging from 1.5 to $3 \mathrm{~nm}$. Three types of wires were studied: pure $\mathrm{Si}$, pure $\mathrm{Si} /$ pure Ge core-shell and $\mathrm{Si}_{0.7} \mathrm{Ge}_{0.3}$ core $/ \mathrm{Si}_{0.3} \mathrm{Ge}_{0.7}$ shell NWs (that corresponds to the synthesized structure). For each system, we analyzed the dependence of the electronic band gap on the diameter, the band structure as well as the spatial wave function localization.

First, as described in detail in the Supporting Information, we found that the band gap value increases as the diameter is decreased in all the type of wires due to the quantum confinement effect. However, while Si NWs show their own trend, the scaling law for the pure-Si/pureGe core-shell and $\mathrm{Si}_{0.7} \mathrm{Ge}_{0.3}$ core $/ \mathrm{Si}_{0.3} \mathrm{Ge}_{0.7}$ shell NWs are characterized by a reduction of the value of the gap with respect to pure Si NWs. This means that our synthesized structure may allow for a modulation of the gap value for a given diameter. The observed similarities with 
the behaviour of the pure-Si/pure-Ge core-shell NWs case might be ascribed to the high concentration of Ge atoms near the surface, which is responsible for a reduction of the gap value. ${ }^{67}$

Results of band structure calculations show that while the band gap is always indirect for $\mathrm{Si}$ NWs at these diameters, it can become direct in the case of $\mathrm{Si}_{0.7} \mathrm{Ge}_{0.3}$ core $/ \mathrm{Si}_{0.3} \mathrm{Ge}_{0.7}$ shell NWs, as reported in Fig. 5 (more details concerning this point are available in the Supporting Information). It is worth to note that we observe a direct band gap also in the case of pure $\mathrm{Si}$ / pure Ge core-shell NWs. Based on the results presented in previous studies, ${ }^{62,66,68}$ we expect the band gap to be direct even at diameters larger that those considered in the present work.
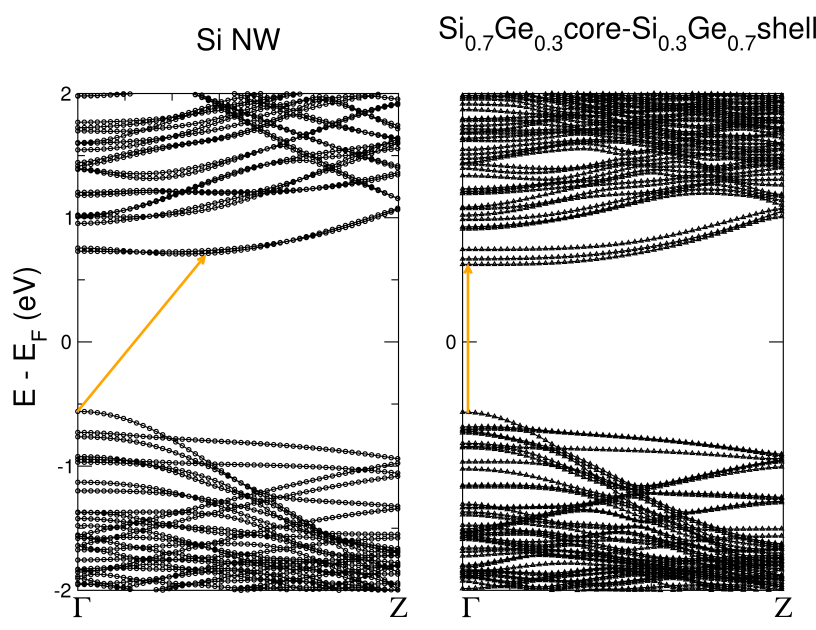

Figure 5: Calculated DFT band structure for a pure Si NW (left panel, black circles) and $\mathrm{Si}_{0.7} \mathrm{Ge}_{0.3}$ core $/ \mathrm{Si}_{0.3} \mathrm{Ge}_{0.7}$ shell NW (right panel, black triangles) with a diameter of $2.25 \mathrm{~nm}$. The character of the band gap is highlighted in both the cases. The thickness of the core and shell for $\mathrm{Si}_{0.7} \mathrm{Ge}_{0.3}$ core $/ \mathrm{Si}_{0.3} \mathrm{Ge}_{0.7}$ shell $\mathrm{NW}$ is $1.5 \mathrm{~nm}$ and $0.75 \mathrm{~nm}$, respectively.

As for the spatial localization of electronic states, wave function plots (see the Supporting Information) clearly demonstrate that for $\mathrm{Si}_{0.7} \mathrm{Ge}_{0.3}$ core $/ \mathrm{Si}_{0.3} \mathrm{Ge}_{0.7}$ shell NWs the valence band states (holes) are mostly located on Ge atoms while the conduction band states (electrons) on $\mathrm{Si}$ atoms. This reflects the tendency for SiGe core-shell NWs to develop a type II band offset at the $\mathrm{Si} / \mathrm{Ge}$ interface. ${ }^{10}$ Though in our composition graded structure the band offset is not completely sharp, the evidence of a different carrier localization for electrons and holes is unambiguous.

The possibility to obtain a direct band gap together with a modulation its value make the $\mathrm{Si}_{0.7} \mathrm{Ge}_{0.3}$ core $/ \mathrm{Si}_{0.3} \mathrm{Ge}_{0.7}$ shell NWs synthesized in this work candidates materials for light emitting devices. Furthermore, the strong charge separation between electrons and hole could find interesting applications in the field of photovoltaics. Due to the novelty of the proposed structures, we cannot compare our theoretical results with experimental measurements that unfortunately are still lacking. Further experimental studies in this direction would be helpful.

\section{Conclusions}

We successfully fabricated core-shell NWs using a simple strategy involving first the growth of a Si-rich NW and second the condensation of a Ge-rich shell (more than 70\%). The approach developed eliminates any contamination of the core-shell interface and produces radial heterostructures with tunable aspect ratio, diameter and a very abrupt interface resulting from a diffusion/segregation limited dynamics. We give examples of ultra-small NWs fully coherent, free of defects, with perfectly passivated surfaces and with $14 \mathrm{~nm} / 7 \mathrm{~nm}$ core/shell diameter/thickness respectively. Results of DFT calculations on composition graded core-shell wires indicate the possibility have a direct band gap whose value can be modulated with respect to the one of pure Si NWs. A pronounced spatial separation of electrons and holes is also observed. We argue that the proposed method and these novel core-shell structures may be crucial for the development of opto-electronic devices decreasing the cost constraints of planar technologies and high quality materials while providing pathways for more efficient mobility of carriers. Their ease of fabrication is furthering their potential for research. Moreover, we are confident that sustained and dedicated integration efforts in this promising area will provide a general technological approach for tran- 
sistor device fabrication.

Acknowledgement The authors thank Thomas Neisius and Martiane Cabie for their help with the microscopy experiments. This work has been carried out thanks to the support of the NANOALLIANCE project. Simulations were made possible thanks to the HPC resources of IDRIS under the allocation i2015097422 made available by GENCI (Grand Equipement National de Calcul Intensif).

\section{References}

(1) Chen, L.; Cai, F.; Otuonye, U.; Lu, W. D. Nano Lett. 2016, 16, 420-426.

(2) Nah, J.; Dillen, D. C.; Varahramyan, K. M.; Banerjee, S. K.; Tutuc, E. Nano Lett. 2012, 12, 108-112.

(3) Yan, H.; Choe, H. S.; Nam, S.; Hu, Y.; Das, S.; Klemic, J. F.; Ellenbogen, J. C.; Lieber, C. M. Nature 2011, 470, 240-244.

(4) Nguyen, B.-M.; Taur, Y.; Picraux, S. T.; Dayeh, S. A. Nano Lett. 2014, 14, 585591.

(5) Liu, E. S.; Dillen, D. C.; Nah, J.; Fallahazad, B.; Kim, K.; Tutuc, E. IEEE T. Electron Dev. 2013, 60, 4027-4033.

(6) Lauhon, L. J.; Gudiksen, M. S.; Wang, D.; Lieber, C. M. Nature 2002, 420, 57-61.

(7) Xiang, J.; Lu, W.; Hu, Y.; Wu, Y.; Yan, H.; Lieber, C. M. Nature 2006, 441, 489-493.

(8) Dillen, D. C.; Wen, F.; Kim, K.; Tutuc, E. Nano Lett. 2016, 16, 392-398.

(9) Fukata, N.; Yu, M.; Jevasuwan, W.; Takei, T.; Bando, Y.; Wu, W.; Wang, Z. L. ACS Nano 2015, 9, 12182-12188.

(10) Amato, M.; Palummo, M.; Rurali, R.; Ossicini, S. Chem. Rev. 2014, 114, 13711412 .
(11) Lu, W.; Xiang, J.; Timko, B. P.; Wu, Y.; Lieber, C. M. Proc. Nat. Acad. Sci. 2005, 102, 10046-10051.

(12) Xiang, J.; Lu, W.; Yongjie,; Wu, Y.; Yan, H.; Lieber, C. M. Nature 2011, 441, 489-493.

(13) Dhungana, K. B.; Jaishi, M.; Pati, R. Nano Lett. 2016, 16, 3995-4000.

(14) Dayeh, S. A.; Wang, J.; Li, N.; Huang, J. Y.; Gin, A. V.; Picraux, S. T. Nano Lett. 2011, 11, 4200-4206.

(15) Yang, J.-E.; Jin, C.-B.; Kim, C.-J.; Jo, M.H. Nano Lett. 2006, 6, 2679-2684.

(16) Day, R. W.; Mankin, M. N.; Lieber, C. M. Nano Lett. 2016, 16, 2830-2836.

(17) Goldthorpe, I. A.; Marshall, A. F.; McIntyre, P. C. Nano Lett. 2008, 8, 4081-4086.

(18) Day, R. W.; Mankin, M. N.; Gao, R.; No, Y.-S.; Kim, S.-K.; Bell, D. C.; Park, H.-G.; Lieber, C. M. Nat. Nanotech. 2015, 10, 345-352.

(19) Dayeh, S. A.; Tang, W.; Boioli, F.; Kavanagh, K. L.; Zheng, H.; Wang, J.; Mack, N. H.; Swadener, G.; Huang, J. Y.; Miglio, L.; Tu, K.-N.; Picraux, S. T. Nano Lett. 2013, 13, 1869-1876.

(20) Dayeh, S. A.; Gin, A. V.; Picraux, S. T. Appl. Phys. Lett. 2011, 98, 163112.

(21) Periwal, P.; Sibirev, N. V.; Patriarche, G.; Salem, B.; Bassani, F.; Dubrovskii, V. G.; Baron, T. Nano Lett. 2014, 14, 5140 5147.

(22) Wen, C.-Y.; Reuter, M. C.; Su, D.; Stach, E. A.; Ross, F. M. Nano Lett. 2015, 15, 1654-1659.

(23) Fukata, N.; Mitome, M.; Sekiguchi, T.; Bando, Y.; Kirkham, M.; Hong, J.-I.; Wang, Z. L.; Snyder, R. L. ACS Nano 2012, 6, 8887-8895.

(24) Zhang, L.; d'Avezac, M.; Luo, J.-W.; Zunger, A. Nano Lett. 2012, 12, 984-991. 
(25) Wang, X.; Tsybeskov, L.; Kamins, T. I.; Wu, X.; Lockwood, D. J. J. Appl. Phys. 2015, 118, 234301.

(26) Irrera, A.; Artoni, P.; Fioravanti, V.; Franzò, G.; Fazio, B.; Musumeci, P.; Boninelli, S.; Impellizzeri, G.; Terrasi, A.; Priolo, F.; Iacona, F. Nanoscale Res. Lett. 2014, 9, 74 .

(27) Kalem, S.; Werner, P.; Talalaev, V. Appl. Phys. A 2013, 112, 561-567.

(28) Amato, M.; Rurali, R. Nano Lett. 2015, 15, 3425-3430.

(29) Markussen, T. Nano Lett. 2012, 12, 46984704.

(30) Moon, J.; Kim, J.-H.; Chen, Z. C.; Xiang, J.; Chen, R. Nano Lett. 2013, 13, 1196-1202.

(31) Zhang, Z.; Dillen, D. C.; Tutuc, E.; Yu, E. T. Nano Lett. 2015, 15, 4303-4310.

(32) Martinez, J. A.; Cho, J.-H.; Liu, X.; Luk, T. S.; Huang, J.; Picraux, S. T.; Sullivan, J. P.; Swartzentruber, B. S. Appl. Phys. Lett. 2013, 102, 103101.

(33) Hu, M.; Poulikakos, D. Nano Lett. 2012, 12, 5487-5494.

(34) Shen, J.-N.; Wu, L.-M.; Zhang, Y.-F. J. Mater. Chem. A 2014, 2, 2538-2543.

(35) Hsiao, T.-K.; Chang, H.-K.; Liou, S.-C.; Chu, M.-W.; Lee, S.-C.; Chang, C.-W. Nat. Nano 2013, 8, 534-538.

(36) Yang, K.; Cantarero, A.; Rubio, A.; D'Agosta, R. Nano Res. 2015, 8, 26112619.

(37) Amato, M.; Ossicini, S.; Rurali, R. Nano Lett. 2012, 12, 2717-2721.

(38) Park, S. B.; Kim, Y. W.; Ko, Y. G.; Kim, K. I.; Kim, I. K.; Kang, H.-S.; Yu, J. O.; Suh, K. P. IEEE J. Solid-St. Circ. 1999, 34, 1436-1445.
(39) Park, J.-T.; Colinge, J. P. IEEE T. Electron Dev. 2002, 49, 2222-2229.

(40) Chau, R.; Kavalieros, J.; Doyle, B.; Murthy, A.; Paulsen, N.; Lionberger, D.; Barlage, D.; Arghavani, R.; Roberds, B.; Doczy, M. A $50 \mathrm{~nm}$ depleted-substrate CMOS transistor (DST). Electron Devices Meeting, 2001. IEDM '01. Technical Digest. International. 2001; pp 29.1.1-29.1.4.

(41) Yu, B.; Chang, L.; Ahmed, S.; Wang, H.; Bell, S.; Yang, C.-Y.; Tabery, C.; Ho, C.; Xiang, Q.; King, T.-J.; Bokor, J.; Hu, C.; Lin, M.-R.; Kyser, D. FinFET scaling to $10 \mathrm{~nm}$ gate length. Electron Devices Meeting, 2002. IEDM '02. International. 2002; pp 251-254.

(42) del Alamo, J. A. Nature 2011, 479, 317 323.

(43) Tezuka, T.; Moriyama, Y.; Nakaharai, S.; Sugiyama, N.; Hirashita, N.; Toyoda, E.; Miyamura, Y.; ichi Takagi, S. Thin Solid Films 2006, 508, 251-255.

(44) Littlejohns, C. G.; Nedeljkovic, M.; Mallinson, C. F.; Watts, J. F.; Mashanovich, G. Z.; Reed, G. T.; Gardes, F. Y. Sci. Rep. 2015, 5, 8288.

(45) Pelloux-Prayer, J.; Cassé, M.; Triozon, F.; Barraud, S.; Niquet, Y.-M.; Rouviére, J.L.; Faynot, O.; Reimbold, G. Solid State Electron. 2016, 125.

(46) Schmidt, V.; Wittemann, J. V.; Senz, S.; Gösele, U. Adv. Mater. 2009, 21, 26812702 .

(47) Singh, N.; Buddharaju, K. D.; Manhas, S. K.; Agarwal, A.; Rustagi, S. C.; Lo, G. Q.; Balasubramanian, N.; Kwong, D. L. IEEE T. Electron Dev. 2008, 55, 3107-3118.

(48) Goldthorpe, I. A.; Marshall, A. F.; McIntyre, P. C. Nano Lett. 2009, 9, 3715-3719.

(49) David, T.; Benkouider, A.; Aqua, J.-N.; Cabie, M.; Favre, L.; Neisius, T.; Abbarchi, M.; Naffouti, M.; Ronda, A.; Liu, K.; 
Berbezier, I. J. Phys. Chem. C 2015, 119, 24606-24613.

(50) David, T.; Liu, K.; Fernandez, S.; Richard, M.-I.; Ronda, A.; Favre, L.; Abbarchi, M.; Benkouider, A.; Aqua, J.-N.; Peters, M.; Voorhees, P.; Thomas, O.; Berbezier, I. J. Phys. Chem. C 2016, 120, 20333-20340.

(51) Amato, M.; Rurali, R. Prog. Surf. Sci. 2016, 91, 1-28.

(52) Oehler, F.; Gentile, P.; Baron, T.; Ferret, P. Nanotechnology 2009, 20, 475307.

(53) Gentile, P.; Solanki, A.; Pauc, N.; Oehler, F.; Salem, B.; Rosaz, G.; Baron, T.; Hertog, M. D.; Calvo, V. Nanotechnology 2012, 23, 215702.

(54) Oehler, F.; Gentile, P.; Baron, T.; Ferret, P.; Den Hertog, M.; RouviẤlre, J. Nano Lett. 2010, 10, 2335-2341.

(55) Buttard, D.; Gentile, P.; Renevier, H. Surf. Sci. 2011, 605, 570 - 576.

(56) Min, B.-G.; Pae, Y. H.; Jun, K. S.; Ko, D.H.; Kim, H.; Cho, M.-H.; Lee, T.-W. J. Appl. Phys. 2006, 100, 16102.

(57) Niquet, Y. M.; Lherbier, A.; Quang, N. H.; Fernández-Serra, M. V.; Blase, X.; Delerue, C. Phys. Rev. B 2006, 73, 165319.

(58) Niquet, Y.-M.; Delerue, C.; Krzeminski, C. Nano Lett. 2012, 12, 3545-3550.

(59) Ossicini, S.; Amato, M.; Guerra, R.; Palummo, M.; Pulci, O. Nanoscale Res. Lett. 2010, 5, 1637-1649.

(60) Ma, D. D. D.; Lee, C. S.; Au, F. C. K.; Tong, S. Y.; Lee, S. T. Science 2003, 299, 1874-1877.

(61) Hÿtch, M.; Snoeck, E.; Kilaas, R. Ultramicroscopy 1998, 74, 131 - 146.

(62) Jomaa, N.; Delerue, C.; Said, M. Superlatt. Microst. 2017, 10\%, 83-90.
(63) Amato, M.; Palummo, M.; Ossicini, S. Phys. Rev. B 2009, 79, 201302.

(64) Peng, X.; Logan, P. Appl. Phys. Lett. 2010, 96, 143119.

(65) Peng, X.; Tang, F.; Logan, P. J. Phys. Cond. Matt. 2011, 23, 115502.

(66) Amato, M.; Palummo, M.; Ossicini, S. Mater. Sci. Eng. B 2012, 177, 705-711.

(67) Iori, F.; Ossicini, S.; Rurali, R. Journal of Applied Physics 2014, 116, 154301.

(68) Peköz, R.; Raty, J.-Y. Phys. Rev. B 2009, 80, 155432. 